Article

\title{
Mild, one-step hydrothermal synthesis of carbon-coated CdS nanoparticles with improved photocatalytic activity and stability
}

\author{
Shuai Zou, Zaihui Fu*, Chao Xiang, Wenfeng Wu, Senpei Tang, Yachun Liu, Dulin Yin \\ National \& Local United Engineering Laboratory for New Petrochemical Materials \& Fine Utilization of Resources, Key Laboratory of Resource \\ Fine-Processing and Advanced Materials of Hunan Province and Key Laboratory of Chemical Biology and Traditional Chinese Medicine Research \\ (Ministry of Education of China), College of Chemistry and Chemical Engineering, Hunan Normal University, Changsha 410081, Hunan, China
}

\section{A R T I C L E I N F O}

Article history:

Received 14 January 2015

Accepted 27 February 2015

Published 20 July 2015

Keywords:

Glucose carbonization

Carbon-coated cadmiun sulfide

Photo-oxidative degradation

Visible light irradiation

Methyl orange

\section{Introduction}

During the past few decades, photocatalytic oxygenation has attracted extensive interest because of its potential application in environmental treatment and the synthesis of fine chemicals [1-3]. Meanwhile, a large number of metal oxide and sulfide semiconductors have been found to be effective photocatalysts in the purification of wastewater and the removal of waste gas [4-6]. Cadmium sulfide (CdS) as a II-VI n-type semiconductor material possesses a low band gap energy $(2.4 \mathrm{eV})$ and good visible light absorption as well as unique photo-electrochemical and photo-physical properties [7-10], and therefore it has been extensively applied to photoelectric conversion, nonlinear op- tics, optical sensors and, especially, in the field of photocatalysis [11-17]. However, CdS is prone to light corrosion reactions in aqueous solution, which shortens its photocatalytic lifetime and results in environmental pollution $[18,19]$. In addition, the photocatalytic activity of CdS is limited owing to its poor adsorption of the organic dye and the rapid recombination rate of its photogenerated electron-hole pairs. Some effective methods have been developed to improve the photocatalytic activity of CdS, such as precious metal deposition [20], metal cation doping [21,22], and semiconductor composites [23-25].

Recently, amorphous carbon as a coating material has received considerable attention because of its aromatic carbon sheet structure and its abundant surface $-\mathrm{OH}$ and $-\mathrm{COOH}$

\footnotetext{
* Corresponding author. Tel: +86-731-88872576; Fax: +86-731-88872531; E-mail: fzhhnnu@126.com This work was supported by the National Natural Science Fundation of China (20873040), the Specialized Research Fund for the Doctoral Program of Higher Education (20124306110005), the Natural Science Fund of Hunan Province (10JJ2007, 14JJ2148), and the Program for Science and Technology Innovative Research Team in Higher Educational Institutions of Hunan Province.

DOI: 10.1016/S1872-2067(15)60827-0 | http://www.sciencedirect.com/science/journal/18722067 | Chin. J. Catal., Vol. 36, No. 7, July 2015
} 
groups that can efficiently reduce the photogenerated electron-hole pair recombination of $\mathrm{CdS}$ by accelerated electron transfer and can improve the adsorption capacity for organic contaminants in wastewater [26-28]. Moreover, the amorphous carbon-coated semiconductors can expand the light absorption range via a photosensitizing effect [27,29-31]. The amorphous carbon material is easily prepared by a simple hydrothermal or solvothermal process at a temperature higher than $160{ }^{\circ} \mathrm{C}$ using glucose or cellulose as a precursor $[27,29,32-35]$. To the best of our knowledge, however, the hydrothermal carbonization of glucose at lower temperatures has not yet been reported. Here, we report the preparation of carbon-coated CdS (CdS@C) nanoparticles by one-step hydrothermal carbonization of glucose under mild conditions and their photocatalytic performance in the visible light triggeredoxidative degradation of methyl orange (MO) aqueous solution.

\section{Experimental}

\subsection{Preparation of catalyst}

All chemicals were of analytical reagent grade purchased from Sinopharm and were used without further purification. Deionized water was used in all experiments. CdS@C hybrid particles were prepared by a one-pot hydrothermal method where, in a typical synthesis, $\mathrm{Cd}(\mathrm{OAc})_{2} \cdot 2 \mathrm{H}_{2} \mathrm{O}(20 \mathrm{mmol})$, $\left(\mathrm{NH}_{2}\right)_{2} \mathrm{CS}$ (24 mmol), and $\mathrm{C}_{6} \mathrm{H}_{12} \mathrm{O}_{6} \cdot \mathrm{H}_{2} \mathrm{O}$ (20 mmol) were dissolved in deionized water $(80 \mathrm{~mL})$ under ultrasonication to form a homogeneous aqueous solution, after which the solution was removed to a 100-mL Teflon-lined stainless autoclave. The sealed autoclave was heated to $130{ }^{\circ} \mathrm{C}$ and maintained at this temperature for various heating times. After cooling to room temperature, the resulting solid particles were collected and washed several times with distilled water and ethanol and subsequently dried in air at $60{ }^{\circ} \mathrm{C}$ for $12 \mathrm{~h}$. Corresponding to the heating time used $(8,10,14,18,20$, and $22 \mathrm{~h})$, the catalyst sample was designated as CdS@C-8, CdS@C-10, CdS@C-14, CdS@C-18, CdS@C-20, and CdS@C-22. For comparison, a pure CdS-18 sample was prepared using the same hydrothermal conditions as for sample CdS@C-18 in the absence of glucose. A typical photocatalyst P25 was purchased from Sinopharm.

\subsection{Characterization of catalyst}

X-ray diffraction (XRD) analysis of the samples was carried out at room temperature on a Y-2000 X-ray diffractometer apparatus using $\mathrm{Cu} K_{\alpha}$ radiation $(\lambda=0.15406 \mathrm{~nm})$ and a graphite monochromator, operated at a voltage of $30 \mathrm{kV}$ and a current of $20 \mathrm{~mA}$. XRD patterns were recorded in the angular range of $20^{\circ}-80^{\circ}$ with a scanning rate $0.05^{\circ} / \mathrm{s}$. Scanning electron microscopy (SEM) analysis was performed with a MIRA3 TESCAN using an accelerating voltage of $20 \mathrm{kV}$, and with the energy-dispersive X-ray spectrometer (EDX) attached to the SEM. High-resolution transmission electron microscopy (HRTEM) images were obtained using a JEM-2100F instrument with a tungsten filament, using an accelerating voltage of 200 $\mathrm{kV}$. Fourier transform infrared (FT-IR) spectra of the samples were obtained on a Nicolet 310 spectrometer in the wavenumber range of $4000-400 \mathrm{~cm}^{-1}$. Ultraviolet to visible light (UV-Vis) diffuse reflectance spectra (DRS) of the samples were recorded from 200 to $800 \mathrm{~nm}$ using a UV-Vis spectrophotometer (UV-3310) with $\mathrm{BaSO}_{4}$ as a reference. Photoluminescence (PL) measurements of the samples were carried out on an F-4600 FL spectrophotometer with the excitation wavelength of $370 \mathrm{~nm}$. Thermogravimetric analysis (TGA) curves were recorded in air flow on a Netzsch Model STA 409PC instrument with a heating rate of $20^{\circ} \mathrm{C} / \mathrm{min}$ from room temperature to 600 ${ }^{\circ} \mathrm{C}$ using $\alpha-\mathrm{Al}_{2} \mathrm{O}_{3}$ as the standard material.

\subsection{Photocatalytic activity test}

Photocatalytic activity of the as-prepared samples for the oxidative degradation of an MO aqueous solution was performed in a photo-reactor built in-house and equipped with a water-cooled condenser $\left(15^{\circ} \mathrm{C}\right)$. A typical procedure was as follows. Catalyst powders $(0.02 \mathrm{~g})$ were dispersed into the MO aqueous solution (10 mg/L, $30 \mathrm{~mL})$, and a 35-W tungsten-bromine lamp with a UV light filter (Osram brand) was immersed in the suspensions. Before illumination, the mixture was magnetically stirred in the dark for 30 min under pure $\mathrm{O}_{2}$ atmosphere to ensure adsorption-desorption equilibrium of the MO dye onto the surface of the catalyst. After given illumination time intervals, the reaction solution $(1 \mathrm{~mL})$ was taken out and centrifuged to remove the catalyst. The obtained filtrate was subjected to an analysis of MO concentration on the UV-Vis spectrometer 1102 using a work wavelength of $465 \mathrm{~nm}$.

\section{Results and discussion}

\subsection{Characterization of photocatalyst}

\subsubsection{XRD results}

Figure 1 shows the XRD patterns of the CdS and CdS@C materials. The CdS-18 exhibits characteristic XRD peaks at $2 \theta=$ $24.9^{\circ}, 26.5^{\circ}, 28.1^{\circ}, 43.9^{\circ}, 47.8^{\circ}$, and $52.0^{\circ}$, which respectively correspond to the (100), (002), (101), (110), (103), and (112) crystal planes of hexagonal CdS (JCPDS 41-1049). In addition, there are no miscellaneous peaks attributed to $\mathrm{CdO}, \mathrm{Cd}$, and other cadmium compound crystals evident in this XRD pattern, indicating that the CdS-18 synthesized under these hydrothermal conditions is of a high quality. The XRD patterns of three catalysts (CdS@C-14, CdS@C-18, and CdS@C-22) are very similar to each other, exhibiting three strong peaks at $2 \theta=26.6^{\circ}$, $43.8^{\circ}$, and $52.1^{\circ}$, which are respectively assigned to the (111), (220), and (311) crystal planes of face-centered cubic (fcc) CdS (JCPDS 89-0440). In addition, a very weak peak at the $2 \theta$ value of $47.8^{\circ}$ and an asymmetry of the (111) crystal plane peak are also noticed in these XRD patterns, which is indicative of the existence of a hexagonal CdS impurity in the hybrid samples. We propose from these findings that the carbon species generated during hydrothermal carbonization of glucose likely hampers the release of $\mathrm{S}^{2-}$ ions and reduces the deposition rate of $\mathrm{CdS}$, thus leading to the formation of dominant cubic CdS crystals [36]. Notably, the typical diffraction peaks attributed to 


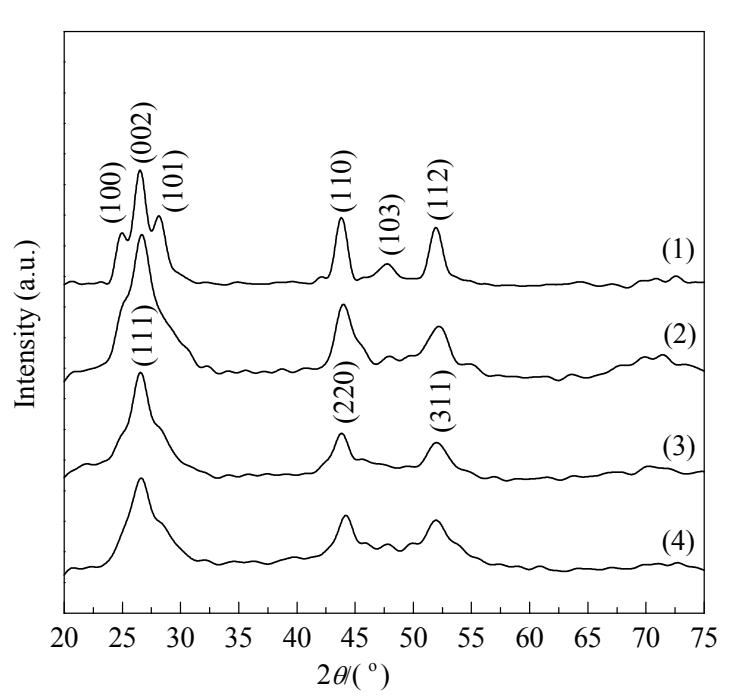

Fig. 1. XRD patterns of CdS-18 (1), CdS@C-14 (2), CdS@C-18 (3), and CdS@C-22 (4).

graphitized carbon are not found in the hybrid samples, indicating that the carbonaceous species coated on the CdS belongs to amorphous carbon with a low degree of graphitization [26]. The average crystal sizes of the samples calculated according to the Scherrer equation follow an increasing sequence of CdS-18 z CdS@C-14 > CdS@C-18 > CdS@C-22 (Table 1), illustrating that the carbonization process of glucose can effectively hinder CdS particle growth with increasing effect with the carbonization time.

\subsubsection{SEM and HRTEM results}

The morphology of both typical materials of CdS-18 and CdS@C-18 is observed by SEM. The image of the CdS-18 sample shows that it is mainly composed of a large number of submicro- and microspheres with particle diameters from several hundreds of nanometers to $2 \mu \mathrm{m}$ that exhibit significant aggregation (Fig. 2(a)) and, as further seen from the enlarged SEM
Table 1

Band gaps, average crystal sizes, and carbon contents of different samples.

\begin{tabular}{lccc}
\hline Sample & $E_{\mathrm{g}}(\mathrm{eV})$ & Crystal size $(\mathrm{nm})$ & $\mathrm{C}(\mathrm{wt} \%)$ \\
\hline CdS-18 & 2.23 & 34.7 & - \\
CdS@C-14 & 2.16 & 11.0 & 7.80 \\
CdS@C-18 (fresh) & 2.15 & 9.8 & 8.76 \\
CdS@C-18 (recovered) & - & - & 5.55 \\
CdS@C-20 & 2.13 & - & 8.82 \\
CdS@C-22 & 2.12 & 9.2 & 12.05 \\
\hline
\end{tabular}

image, the surface of CdS-18 is rough (Fig. 2(b)). The CdS@C-18 sample, however, possesses well-defined nanospheres approximately $500 \mathrm{~nm}$ in diameter, where most of the particles exhibit mono-dispersion and a uniform size (Fig. 2(c) and (d)). Moreover, the recovered CdS@C-18 possesses a similar morphology to the fresh one (Fig. 2(e) vs 2(d)), indicating that the carbon coating layer can effectively improve the stability of CdS particles. Fig. 2(f)-(h) shows the HRTEM images of three individual CdS@C particles, in which a carbon layer coated on the surface of the CdS is clearly observed whose thickness gradually increases as the carbonization time is prolonged from 14 to $22 \mathrm{~h}$, along with an improvement of the deposition uniformity on the surface of CdS.

\subsubsection{EDX results}

The C, N, S, and Cd elements on the surface of CdS-18 and CdS@C-18 are detected by EDX. As shown in Fig. 3(a), a certain amount of $\mathrm{C}$ and $\mathrm{N}$ elements can be detected on the surface of CdS-18 in addition to the expected $\mathrm{Cd}$ and $\mathrm{S}$, which indicates the deposition on the surface of CdS of organic impurities containing $\mathrm{C}$ and $\mathrm{N}$ elements that likely originate from the decomposed products of thiourea. Notably, the $\mathrm{C}$ and $\mathrm{N}$ contents measured on the surface of CdS@C-18 (Fig. 3(b)) are significantly higher than those on the surface of CdS-18, indicating that the deposition of glucose-carbonized species on the surface of CdS has occurred and thiourea should participate somewhat in the formation of glucose carbonization species.



Fig. 2. SEM images of CdS-18 (a, b), fresh CdS@C-18 (c, d), and recovered CdS@C-18 (e); HRTEM images of CdS@C-14 (f), CdS@C-18(g), and CdS@C-22 (h). 

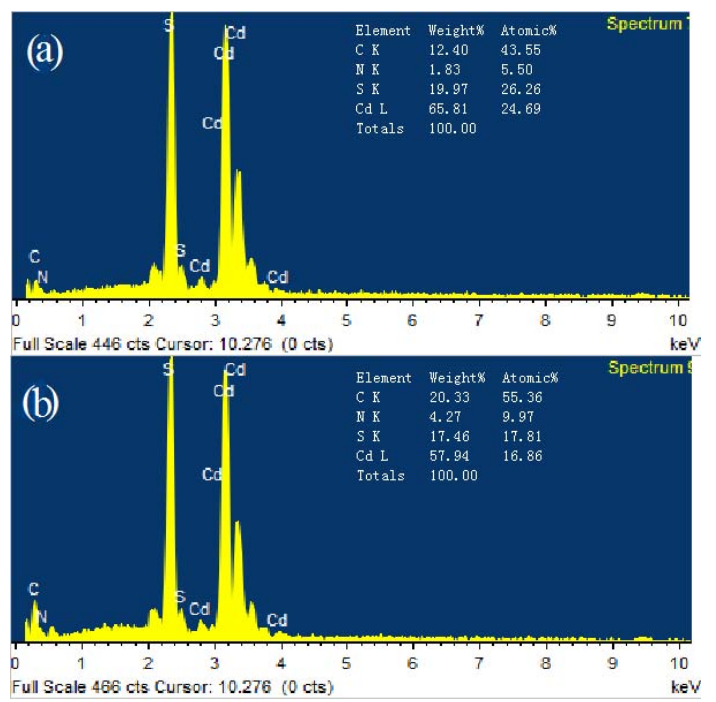

Fig. 3. EDX spectroscopy images of CdS-18 (a) and CdS@C-18 (b).

\subsubsection{FT-IR spectra}

Figure 4 shows the FT-IR spectra of various CdS@C samples and a pure carbon material prepared from the hydrothermal carbonization of glucose, wherein all of the samples exhibit very similar FT-IR absorption bands. Among these FT-IR bands, the wide absorption peak at $3000-3500 \mathrm{~cm}^{-1}$ corresponds to the stretching vibration of $-\mathrm{OH}$ groups; the absorption bands near $2920 \mathrm{~cm}^{-1}$ are attributed to $\mathrm{C}-\mathrm{H}$ vibrations; the bands at 1714 and $1620 \mathrm{~cm}^{-1}$ are ascribed to $\mathrm{C}=\mathrm{O}$ and $\mathrm{C}=\mathrm{C}$ stretching vibrations, respectively; and the absorption bands in the 1000-1300 $\mathrm{cm}^{-1}$ region should correspond to the $\mathrm{C}-\mathrm{OH}$ stretching and $-\mathrm{OH}$ bending vibrations. In addition, a weak absorption peak at $878 \mathrm{~cm}^{-1}$ attributable to $\mathrm{C}-\mathrm{H}$ plane bending vibrations is noticed in the FT-IR spectrum of the thick carbon layer-containing sample (CdS@C-22). The presence of these characteristic bands further reveals that the surface of the CdS@C samples is coated with an amorphous carbon layer bearing abundant $-\mathrm{OH}$ and $\mathrm{C}=\mathrm{O}$ functional groups [35].

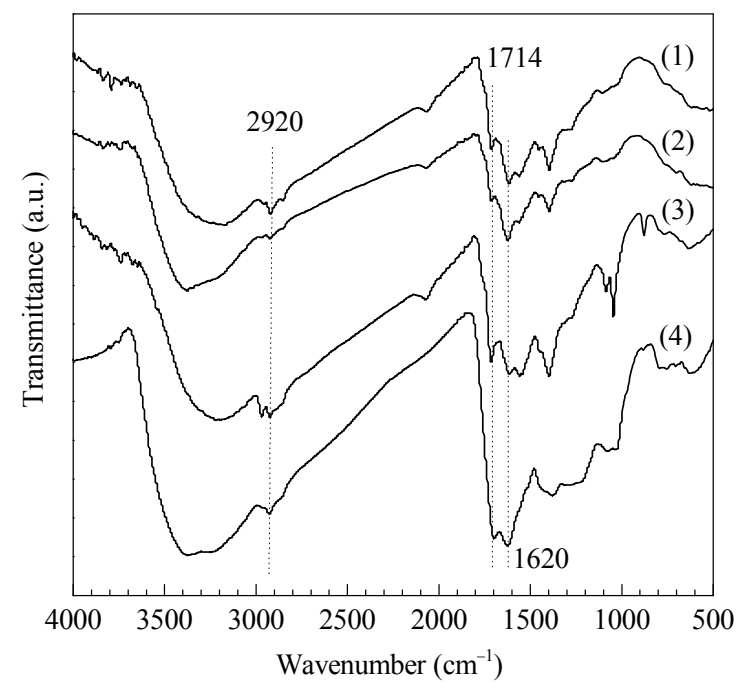

Fig. 4. FT-IR spectra of CdS@C-14 (1), CdS@C-18 (2), CdS@C-22 (3), and pure $C$ (4).

\subsubsection{UV-Vis DRS}

Figure 5 shows the UV-Vis DRS spectra of samples. When compared with the CdS-18 sample, all of the carbon-coated CdS samples, in addition to the characteristic bands assigned to CdS, exhibit an enhanced visible-light absorption in the $550-800 \mathrm{~nm}$ range, where the absorbance in this visible region slightly increases with the carbonization time. This should be assigned to the characteristic absorption of the carbonized species coated on the surface of the CdS, which can be supported by the DRS of a pure glucose-carbonized material. These findings illustrate that the carbonization species of glucose as a sensitizer can broaden the $\mathrm{CdS}$ absorption range for visible light. According to the equation $(\alpha h v)^{2}=A\left(h v-E_{\mathrm{g}}\right)$, where $\alpha$ is the absorption coefficient, $v$ is the light frequency, $E_{\mathrm{g}}$ is the band gap, and $A$ is a constant [37], the band gap of CdS-18 is estimated to be 2.23 $\mathrm{eV}$, which is lower than that of the bulk CdS (2.4 eV) [38-41]. The band gaps optically calculated this way for these carbon-coated CdS materials are found to be between 2.12 and $2.16 \mathrm{eV}$ (Table 1) and narrower than that of the CdS-18, which is likely because of the differences of crystalline phase and crystal sizes, as well as surface modification of the carbonized species.

\subsubsection{PL spectra}

The efficiency of charge trapping and the recombination of photo-induced electrons and holes in semiconductors can be detected by the PL spectrum. Figure 6 shows the PL spectra
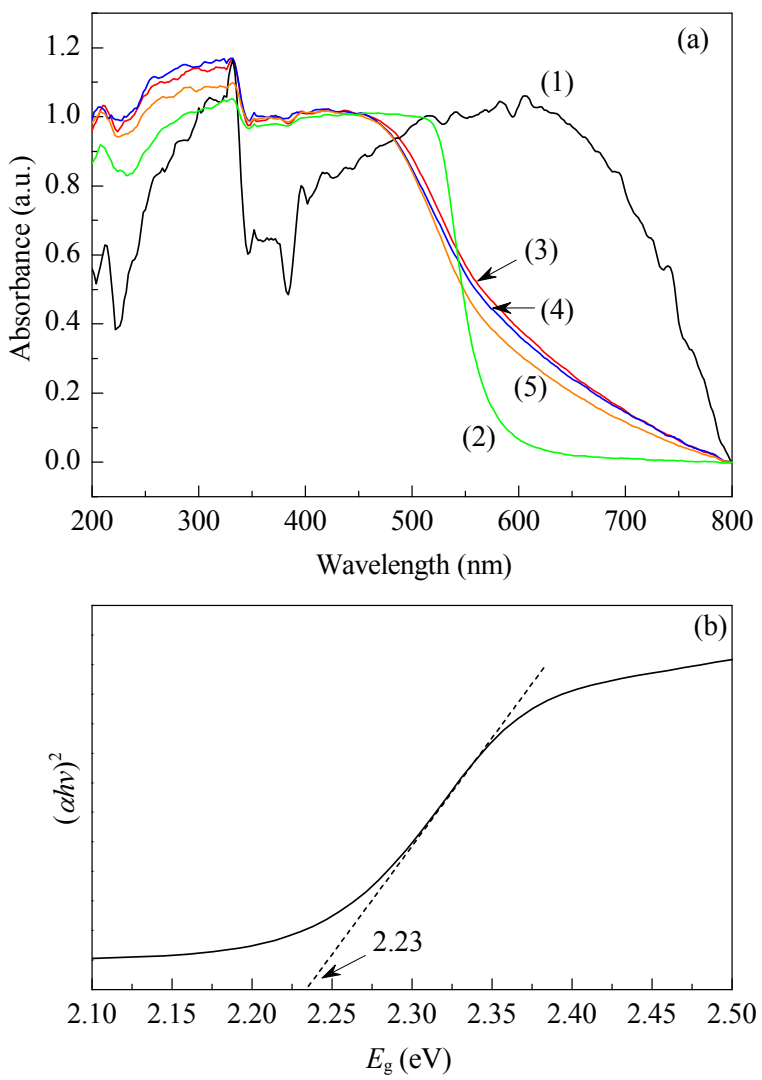

Fig. 5. (a) UV-Vis DRS spectra of C (1), CdS-18 (2), CdS@C-20 (3), CdS@C-18 (4), and CdS@C-14 (5); (b) Plot of $(a h v)^{2}$ vs the energy of absorbed light for a typical CdS-18 sample. 


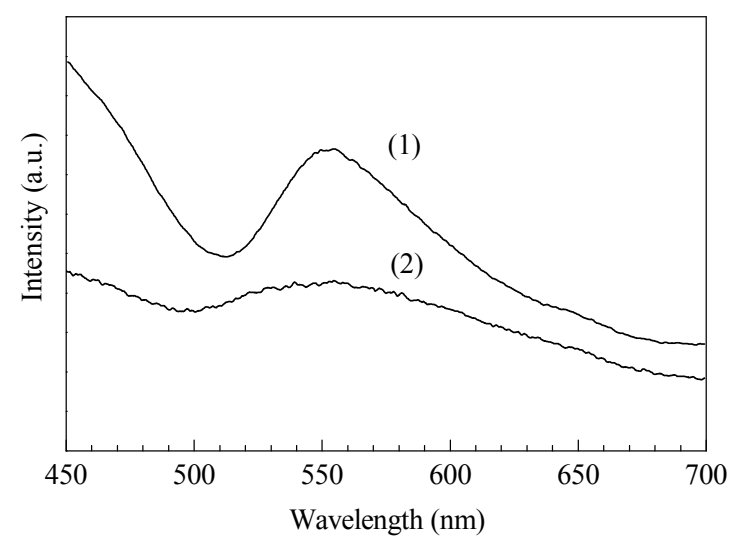

Fig. 6. PL spectra of CdS-18 (1) and CdS@C-18 (2) with an excitation wavelength of $370 \mathrm{~nm}$.

(excited at $370 \mathrm{~nm}$ ) of the typical samples CdS-18 and CdS@C-18. The PL intensity of CdS@C-18 about 550 nm is much weaker than that of CdS-18, supporting the theory that the amorphous carbon species can effectively create exciton separation interfaces and carrier transporting pathways, and that a highly efficient interfacial charge transfer exists between the carbon and CdS. Consequently, the recombination of photogenerated electron-hole pairs on CdS can be efficiently restrained $[42,43]$, leading to a dramatic decrease in the PL intensity of CdS@C-18.

\subsubsection{TGA results}

Figure 7 compares the TGA curves of samples CdS-18 and CdS@C-18 before and after photo-reaction, and the corresponding differential thermogravimetric (DTG) curves. Three main peaks of weight loss are observed in the range $80-600{ }^{\circ} \mathrm{C}$ in the DTG curve of fresh CdS-18, where the first weak peak at $95{ }^{\circ} \mathrm{C}$ should arise from the evaporation of adsorbed water, the second strong peak at $382{ }^{\circ} \mathrm{C}$ is assigned to the oxidative corrosion process of CdS-18, while the assignment of the third peak at $527{ }^{\circ} \mathrm{C}$ is unclear at present. In comparison, fresh CdS@C-18 exhibits a stronger DTG curve dehydration peak at $95{ }^{\circ} \mathrm{C}$, indicating that it possesses good hydrophilicity, and its maximum weight loss peak at $350{ }^{\circ} \mathrm{C}$ should originate from combustion decomposition of the carbon layer-coated CdS [44]. Notably, the weight loss peak attributed to the oxidative corrosion of CdS in the fresh CdS@C-18 shifts to a higher temperature region $\left(398^{\circ} \mathrm{C}\right)$, demonstrating that the coated carbon layer can provide the $\mathrm{CdS}$ with a stronger anti-oxidation corrosion. In addition, the other CdS@C hybrid materials exhibit very similar thermal decomposition behavior to the typical CdS@C-18, and the carbon contents of the CdS@C samples calculated from their carbon weight loss peaks are found to be proportional to their carbonization time (Table 1). Notably, the weight loss peak at $382{ }^{\circ} \mathrm{C}$ of the recovered CdS-18 (inset of Fig. 7) is obviously smaller than that of the fresh CdS-18 sample, perhaps implying that the photo-oxidative corrosion on the surface of CdS-18 occurs during the photocatalytic degradation of MO. The DTG curve of the recovered CdS@C-18 sample illustrates that the carbon weight loss peak is obviously weaker and its carbon content is lower than that of the fresh CdS@C-18 sam-

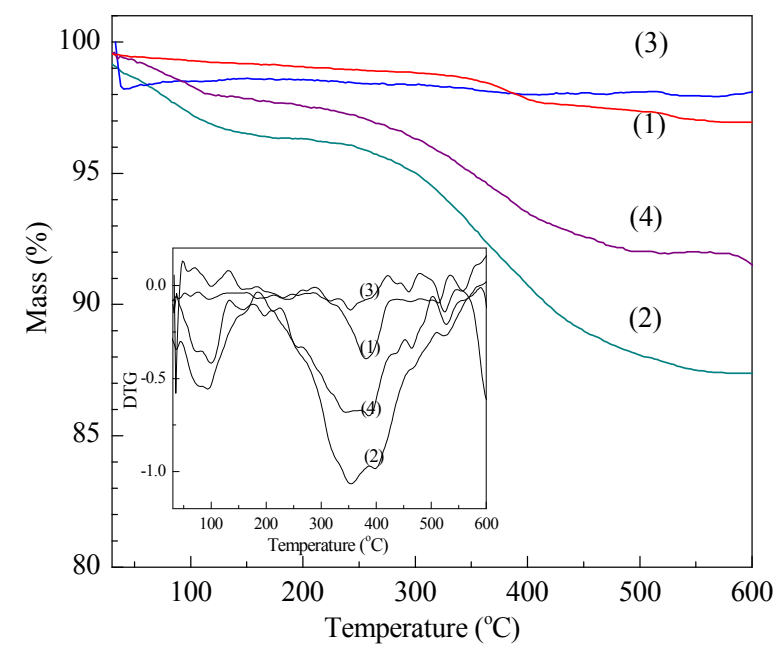

Fig. 7. TGA curves of fresh CdS-18 (1) and CdS@C-18 (2) and recovered CdS-18 (3) and CdS@C-18 (4); Inset: DTG curves.

ple (Table 1). This indicates that the amorphous carbon is somewhat unstable and has a tendency to fall off the surface of the catalyst. However, the weight loss peak at $398{ }^{\circ} \mathrm{C}$ of the recovered CdS@C-18 sample is scarcely changed compared with that of the fresh sample, also indicating that the coated carbon layer can protect the inner CdS nanoparticles from photo-oxidative corrosion during the degradation of MO, which is in agreement with the SEM results.

\subsection{Photocatalytic performance}

The photocatalytic activity of the CdS-18 and CdS@C-18 materials is investigated using the degradation of MO dye in aqueous solution under visible light irradiation, with the typical catalyst $\mathrm{TiO}_{2}$ (P25) used as the reference. As shown in Fig. 8(a), the self-degradation of MO in the absence of a photocatalyst does not occur, indicating that the MO dye is stable under visible light irradiation. A remarkable degradation of MO dye is observed in the presence of these catalysts, however, with the CdS-18 and typical CdS@C-18 catalysts exhibiting a higher activity than the P25 catalyst. The catalytic activity for degradation of MO on P25 under visible light illumination can be attributed to the sensitization of the MO dye, which extends the absorption of P25 to the visible light region [27]. Figure 8(c) shows the temporal evolution of the absorption spectra during the photodegradation of the MO dye using CdS-18, where the maximum absorption peak of MO at $465 \mathrm{~nm}$ continuously decays with illumination time, along with a change of the orange solution color from deep to light. Notably, when the reaction mixture is stirred for $30 \mathrm{~min}$ without light illumination, a slight decrease in the MO concentration is noticed for CdS-18 and, to a greater extent, for CdS@C-18. This decrease in MO concentration originates from adsorption of MO by the catalyst, wherein CdS@C-18 possesses a higher adsorption capacity for MO molecules than CdS-18 because of its surface hydrophilicity. When compared with CdS-18, CdS@C-18 exhibits a slightly lower degradation rate at illumination times less than $3 \mathrm{~h}$, after which it exhibits enhanced photocatalytic efficiency and ultimately 

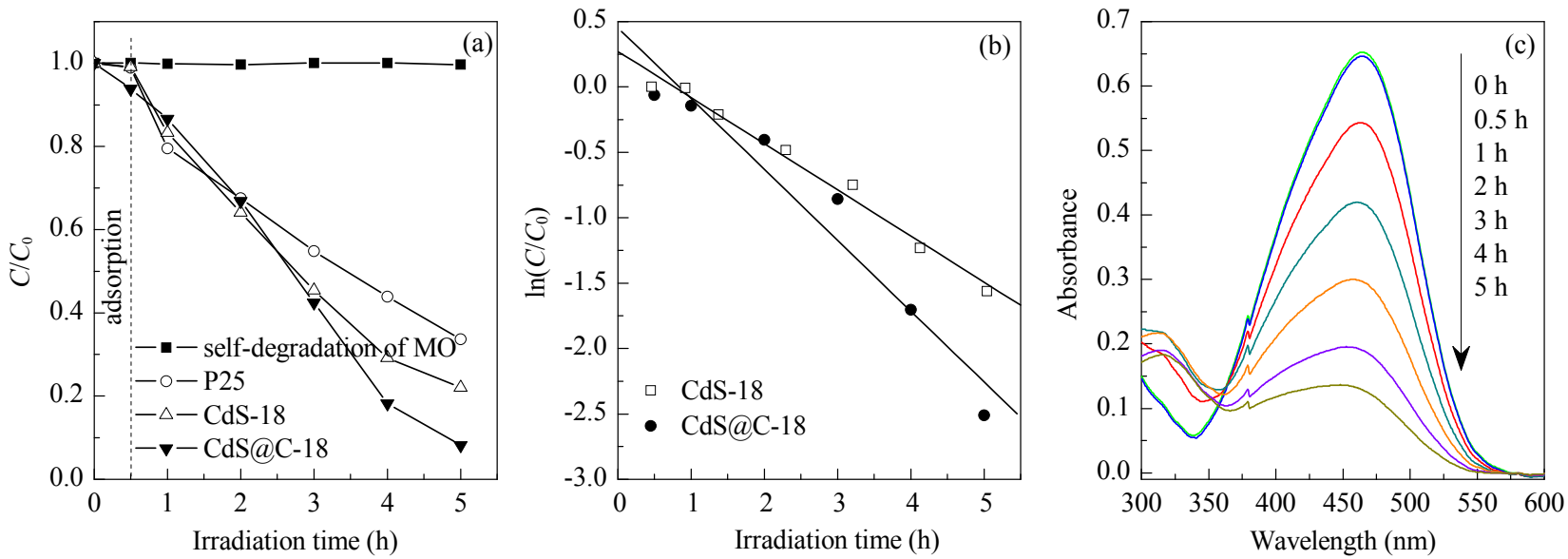

Fig. 8. A comparison of the photocatalytic activity (a) and the natural logarithm (b) of the photocatalytic activity of P25, CdS-18, and CdS@C-18 as a function of irradiation time; (c) UV-Vis absorption spectra of MO in the presence of CdS-18 for various irradiation times.

achieves a higher degradation rate at $5 \mathrm{~h}(92 \%$ vs $78 \%)$. Also, the apparent reaction rate constant $(k)$ calculated from Fig. 8(b) supports that the photocatalytic activity of CdS@C-18 $(k$, $\left.0.5417 \mathrm{~h}^{-1}\right)$ is higher than that of CdS-18 $\left(k, 0.3232 \mathrm{~h}^{-1}\right)$, which may be owing to the following reasons. First, the amorphous carbon layer coated on the CdS has abundant polar $-\mathrm{OH}$ and - $\mathrm{COOH}$ groups, which enables MO molecules to become enriched on its surface. Second, the CdS@C-18, possessing a small particle size and good dispersion, should accelerate a migration of the photogenerated electron and hole pairs toward its surface. Third, the dominant cubic CdS phase possesses a superior photocatalytic activity than the hexagonal phase [45].

In the following experiments, the photocatalytic performance of other CdS@C hybrid materials prepared at various carbonization times is determined using the degradation of MO aqueous solution under visible light illumination. As shown in Fig. 9, the degradation efficiency of CdS@C gradually increases with the carbonization time, ultimately reaching its highest value at $18 \mathrm{~h}$. This degradation efficiency improvement may be owing to the improved uniformity of the surface carbon layer on the CdS, as supported by the HRTEM images in Fig. 2(f)-(h). For carbonization times greater than $18 \mathrm{~h}$, the degradation efficiency slightly decreases, which is likely owing to the

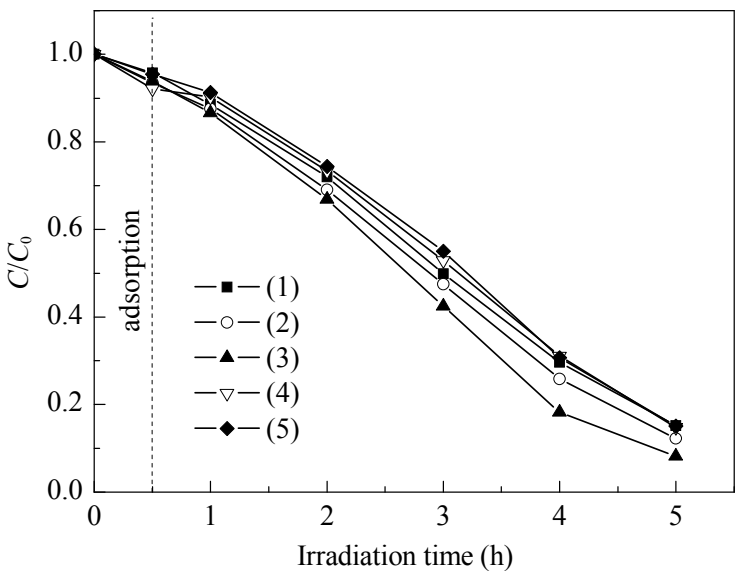

Fig. 9. Visible light photocatalytic activity of CdS@C-8 (1), CdS@C-14 (2), CdS@C-18 (3), CdS@C-20 (4), and CdS@C-22 (5). shielding effect of the thick carbon layer described previously $[26,46]$.

Finally, the catalyst repeatability for visible light-triggered degradation of MO dye aqueous solution is determined using CdS-18 and CdS@C-18 as catalysts. It is seen from Fig. 10(a) that the degradation rate of MO with CdS-18 gradually and slowly decreases with increasing recycling time, which is likely owing to a slight photo-oxidative corrosion on the surface of CdS-18, as supported by the TGA characterization results. Interestingly, the CdS@C-18 catalyst recovered after the first operation exhibits an obviously enhanced photocatalysis efficiency and achieves a higher degradation rate at $3 \mathrm{~h}$ than that of the fresh catalyst (89\% vs $70 \%$, Fig. $10(\mathrm{~b})$ ). This is likely
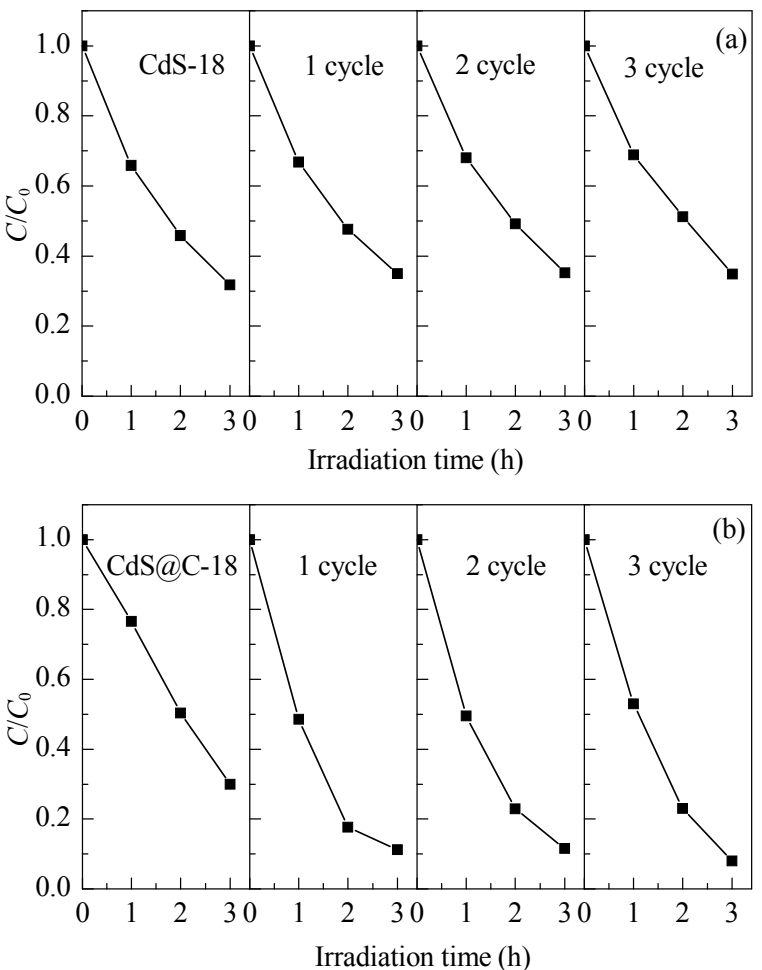

Fig. 10. The catalyst repeatability in the photocatalytic degradation of MO using CdS-18 (a) and CdS@C-18 (b) as catalysts. 
because the carbon layer coated on the surface of the CdS, as described in the TGA characterization results, becomes thin after the first run, thereby improving its internal optical absorption for subsequent photodegradation. Notably, the degradation rate of MO in the following two recycling runs is identical to that obtained in the first recycling run, indicating that the carbon-coated CdS catalyst has excellent repeatability.

\subsection{Possible preparation and photocatalysis mechanisms}

\subsubsection{Preparation mechanism}

Based on these results and those in previous studies [47-49], it is apparent that the formation of CdS@C hybrid particles is accurately described by the following reaction pathway (Scheme 1). First, the free $\mathrm{Cd}^{2+}$ ion in the solution easily reacts with thiourea to generate a $\mathrm{Cd}\left(\mathrm{CH}_{3} \mathrm{COO}\right)_{2}\left(\left(\mathrm{NH}_{2}\right)_{2} \mathrm{CS}\right)_{2}$ complex, which is followed by the decomposition of this complex to obtain the CdS nuclei at an elevated temperature and pressure [47]. At the same time, the alkali $\mathrm{NH}_{3} \cdot \mathrm{H}_{2} \mathrm{O}$ generated from the decomposition of this complex can catalyze the various chemical conversions of glucose under mild hydrothermal conditions, leading to the formation of various soluble aromatic compounds and oligosaccharides and their polymers $[48,49]$. The resulting polymers can be absorbed on the surface of the CdS nuclei and are further carbonized to a hydrophilic carbon colloid layer. In this process, thiourea plays the dual role of providing a sulfur source and catalyzing the hydrothermal carbonization of glucose.

\subsubsection{Photocatalysis mechanism}

According to some published work [50-56], the photo-reaction results found herein can be best explained as follows (Scheme 2). When the CdS@C hybrid material is irradiated with visible light, its amorphous surface carbon can absorb visible light and, in turn, stimulate CdS to generate electron-hole $\left(\mathrm{e}^{-} / \mathrm{h}^{+}\right)$pairs [50]. These photogenerated $\mathrm{e}^{-} / \mathrm{h}^{+}$pairs then react with the oxidants/reducers adsorbed on the CdS surface (usually $\mathrm{O}_{2} / \mathrm{OH}^{-}$) to produce active oxygen radicals (e.g., $\cdot \mathrm{O}_{2}, \cdot \mathrm{OH}$ ), where the latter can lead to the subsequent degradation of MO dyes [51-53]. Significantly, the carbon species coated on the surface of CdS plays an important role in

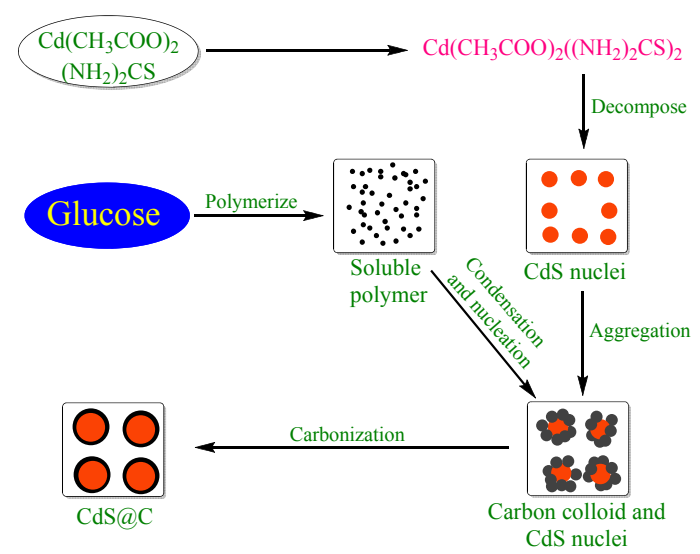

Scheme 1. A schematic model for the growth of CdS@C hybrid particles.

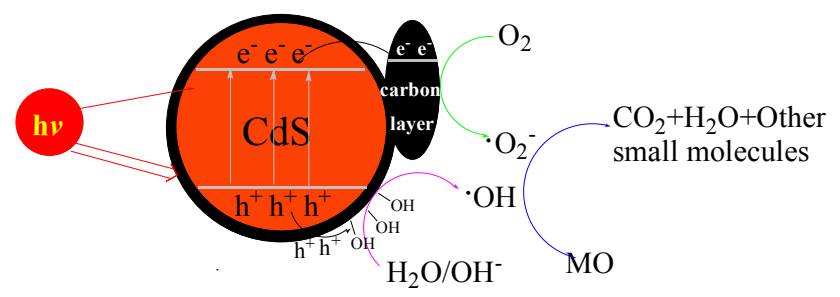

Scheme 2. A schematic diagram of the charge transfer process for the CdS@C hybrid particle photocatalytic degradation of MO.

protecting the inner CdS from photo-oxidative corrosion and preventing the electron-hole pairs from recombining [54], as well as improving the transfer rate of the photogenerated electrons from the CdS surface to the organic pollution through the carbon layer $[55,56]$.

\section{Conclusions}

For the first time we develop a one-step hydrothermal method for the preparation of carbon-coated CdS nanospheres. The present method has the advantage of mild hydrothermal operating conditions, which makes the preparation process of the catalyst simple and environmentally friendly, and the obtained catalyst exhibits enhanced photocatalytic activity and stability for visible light-driven oxidative degradation of MO in aqueous solution. It is anticipated that this kind of catalyst will have competitive potential for highly efficient photocatalytic degradation of organic dye wastewater after further improvement of the photocatalytic performance.

\section{References}

[1] Zhu L, Jo S B, Ye S, Ullah K, Oh W C. Chin J Catal (催化学报), 2014, 35: 1825

[2] Li X Y, Chen G H, Po-Lock Y, Kutal C. J Chem Technol Biotechnol, 2003, 78: 1246

[3] Almeida A R, Moulijn J A, Mul G. J Phys Chem C, 2008, 112: 1552

[4] Hamid S B A, Tan T L, Lai C W, Samsudin E M. Chin J Catal (催化学 报), 2014, 35: 2014

[5] Lettmann C, Hildenbrand K, Kisch H, Macyk W, Maier W F. Appl Catal B, 2001, 32: 215

[6] Taranto J, Frochot D, Pichat P. Ind Eng Chem Res, 2007, 46: 7611

[7] Khan Z, Chetia T R, Vardhaman A K, Barpuzary D, Sastri C V, Qureshi M. RSC Adv, 2012, 2: 12122

[8] Cao J, Sun J Z, Hong J, Li H Y, Chen H Z, Wang M. Adv Mater, 2004, 16: 84

[9] Karan S, Mallik B.J Phys Chem C, 2007, 111: 16734

[10] Podborska A, Gaweł B, Pietrzak Ł, Szymańska I B, Jeszka J K, Łasocha W, Szaciłowski K. J Phys Chem C, 2009, 113: 6774

[11] Wang S M, Liu P, Wang X X, Fu X Z. Langmuir, 2005, 21: 11969

[12] Li X L, Jia Y, Cao A Y. ACS Nano, 2010, 4: 506

[13] Cao M, Li L, Zhang B L, Huang J, Tang K, Cao H, Sun Y, Shen Y. J Alloys Compd, 2012, 530: 81

[14] Yang H H, Kershaw S V, Wang Y, Gong X Z, Kalytchuk S, Rogach A L, Teoh W Y.J Phys Chem C, 2013, 117: 20406

[15] Ferancová A, Rengaraj S, Kim Y, Labuda J, Sillanpää M. Biosens Bioelectron, 2010, 26: 314

[16] Hu Y, Liu Y, Qian H S, Li Z Q, Chen J F. Langmuir, 2010, 26: 18570

[17] Yan J J, Wang K, Xu H, Qian J, Liu W, Yang X W, Li H M. Chin J Catal 


\title{
Graphical Abstract
}

Chin. J. Catal., 2015, 36: 1077-1085 doi: 10.1016/S1872-2067(15)60827-0

\section{Mild, one-step hydrothermal synthesis of carbon-coated CdS nanoparticles with improved photocatalytic activity and stability}

Shuai Zou, Zaihui Fu*, Chao Xiang, Wenfeng Wu, Senpei Tang, Yachun Liu, Dulin Yin Hunan Normal University

This paper describes carbon-coated CdS (CdS@C) nanoparticles, prepared via a convenient one-step hydrothermal carbonization method, that exhibit enhanced photocatalytic activity and stability for visible light-triggered oxidative degradation of methyl orange in aqueous solution.

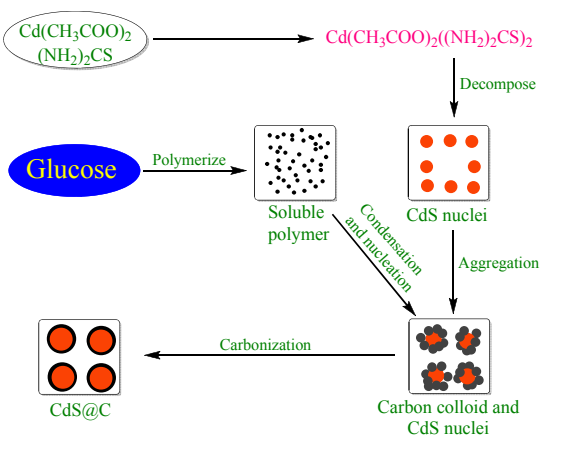

(严佳佳, 王坤, 许晖, 钱静, 刘巍, 杨兴旺, 李华明. 催化学报), 2013, 34, 1876.

[18] Mi Q, Chen D Q, Hu J C, Huang Z X, Li J L. Chin J Catal (米倩, 陈带全, 胡军成, 黄正喜,李金林. 催化学报), 2013, 34: 2138

[19] Kudo A, Miseki Y. Chem Soc Rev, 2009, 38: 253

[20] Silva L A, Ryu S Y, Choi J, Choi W, Hoffmann M R. J Phys Chem C, 2008, 112: 12069

[21] Boxi S S, Paria S. RSC Adv, 2014, 4: 37752

[22] Luo M, Liu Y, Hu J C, Liu H, Li J L. ACS Appl Mater Interfaces, 2012, 4: 1813

[23] Park C Y, Ghosh T, Meng Z D, Kefayat U, Vikram N, Oh W C. Chin J Catal (催化学报), 2013, 34: 711

[24] Kar A, Kundu S, Patra A. RSC Adv, 2012, 2: 10222

[25] Yan H J, Yang J H, Ma G J, Wu G P, Zong X, Lei Z B, Shi J Y, Li C. J Catal, 2009, 266: 165

[26] Li Y Y, Liu J P, Huang X T, Yu J G. Dalton Trans, 2010, 39: 3420

[27] Ren W J, Ai Z H, Jia F L, Zhang L Z, Fan X X, Zou Z G. Appl Catal B, 2007, 69: 138

[28] Ge S X, Jia H M, Zhao H X, Zheng Z, Zhang L Z. J Mater Chem, 2010, 20: 3052

[29] Hu Y, Gao X H, Yu L, Wang Y R, Ning J Q, Xu S J, Lou X W. Angew Chem Int Ed, 2013, 52: 5636

[30] Xu C K, Killmeyer R, Gray M L, Khan S U M. Appl Catal B, 2006, 64: 312

[31] Lee D K, Cho I S, Lee S, Bae S T, Noh J H, Kim D W, Hong K S. Mater Chem Phys, 2010, 119: 106

[32] Liang H W, Zhang W J, Ma Y N, Cao X, Guan Q F, Xu W P, Yu S H. ACS Nano, 2011, 5: 8148

[33] Hu B, Wang K, Wu L H, Yu S H, Antonietti M, Titiriciet M M. Adv Mater, 2010, 22: 813

[34] Wang G X, Liu H, Liu J, Qiao S Z, Lu G M, Munroe P, Ahn H. Adv Mater, 2010, 22: 4944

[35] Sun X M, Li Y D. Angew Chem Int Ed, 2004, 43: 597
[36] Sasikala G, Thilakan P, Subramanian C. Sol Energy Mater Sol Cells, 2000, 62: 275

[37] Fu H B, Pan C S, Yao W Q Zhu Y F.J Phys Chem B, 2005, 109: 22432

[38] Weller H. Angew Chem Int Ed, 1993, 32: 41

[39] Unni C, Philip D, Smitha S L, Nissamudeen K M, Gopchandran K G. Spectrochim Acta A, 2009, 72: 827

[40] Shen S H, Guo L J, Chen X B, Ren F, Mao S S. Int J Hydrogen Energy, 2010, 35: 7110

[41] Yang F, Yan N N, Huang S, Sun Q, Zhang L Z, Yu Y. J Phys Chem C, 2012, 116: 9078

[42] Liu Y, Zhou M J, Hu Y, Qian H S, Chen J F, Hu X. CrystEngComm, 2012, 14: 4507

[43] Yu J G, Ma T T, Liu S W. Phys Chem Chem Phys, 2011, 13: 3491

[44] Zhong J, Chen F, Zhang J L. J Phys Chem C, 2010, 114: 933

[45] Mau A W H, Huang C B, Kakuta N, Bard A J, Campion A, Fox M A, White J M, Webber S E. J Am Chem Soc, 1984, 106: 6537

[46] Zhang L W, Fu H B, Zhu Y F. Adv Funct Mater, 2008, 18: 2180

[47] Bao N Z, Shen L M, Takata T, Domen K, Gupta A, Yanagisawa K, Grimes C A.J Phys Chem C, 2007, 111: 17527

[48] Peng Q, Dong Y J, Li Y D. Angew Chem Int Ed, 2003, 42: 3027

[49] Sakaki T, Shibata M, Miki T, Hirosue H, Hayashi N. Bioresour Technol, 1996, 58: 197

[50] Li H T, He X D, Kang Z H, Huang H, Liu Y, Liu J L, Lian S Y, Tsang C H A, Yang X B, Lee S T. Angew Chem Int Ed, 2010, 49: 4430

[51] Kang Z H, Tsang C H A, Wong N B, Zhang Z D, Lee S T. J Am Chem Soc, 2007, 129: 12090

[52] Kang Z H, Liu Y, Tsang C H A, Ma D D, Fan X, Wong N B, Lee S T. Adv Mater, 2009, 21: 661

[53] Wang W, Gu B H, Liang L Y, Hamilton W.J Phys Chem B, 2003, 107: 3400

[54] Sato S. Langmuir, 1988, 4: 1156

[55] Li Y Y, Liu J P, Huang X T. Nanoscale Res Lett, 2008, 3: 365

[56] Liu Y, Yu Y X, Zhang W D. J Alloys Compd, 2013, 569: 102

\section{一步温和水热法制备具有改善光催化活性和稳定性的碳包覆 CdS 纳米粒子}

\author{
邹帅，伏再辉，向超，吴文锋，汤森培，刘亚纯，尹笃林
}

湖南师范大学化学化工学院, 石化新材料与资源精细利用国家地方联合工程实验室,

资源精细化与先进材料湖南省高校重点实验室，化学生物学及中药分析教育部重点实验室，湖南长沙410081

摘要: 首次报道在 $130^{\circ} \mathrm{C}$ 低温条件下, 以乙酸镉和葡萄糖分别作为镉源和碳源, 硫䏱同时充当硫源和葡萄糖水热碳化的催化剂, 通 过一步水热碳化法制备了碳包覆的 $\mathrm{CdS}(\mathrm{CdS} @ \mathrm{C})$ 纳米材料. 与相同条件下制备的纯CdS相比,合成的 $\mathrm{CdS} @ \mathrm{C}$ 粒子具有更小的粒子 
尺寸、良好的分散性以及更均匀的粒子分布. 而且,葡萄糖在水热碳化过程中能够促使 CdSS优先形成立方晶相. 此外,粒子表面的碳 物种能拓宽 $\mathrm{CdS}$ 的可见光吸收范围, 稍微降低它的带隙能, 减缓 $\mathrm{CdS}$ 的光生电子-空穴对的复合和光腐蚀. 因此, 它能改善 $\mathrm{CdS}$ 在可见 光辐射下催化氧化降解甲基橙的活性和稳定性.

关键词：葡萄糖碳化；碳包覆的硫化镉; 光催化降解；可见光；甲基橙

收稿日期: 2015-01-14. 接受日期: 2015-02-27. 出版日期: 2015-07-20.

*通讯联系人. 电话: (0731)88872576; 传真: (0731)88872531; 电子信箱: fzhhnnu@126.com

基金来源：国家自然科学基金(20873040); 高等学校博士学科点专项科研基金(20124306110005); 湖南省自然科学基金(10JJ2007, 14JJ2148); 湖南省高校科学技术创新团队.

本文的英文电子版由Elsevier出版社在ScienceDirect上出版(http://www.sciencedirect.com/science/journal/18722067). 